\title{
Residual Effects of Moisture Stressed Seedlings in the Nursery on Field Performance of Cacao Genotypes
}

\author{
Agele", S.O. Olayemi, L.U. Aiyelari, O.P., Adesida, A. \\ Plant Physiology \& Ecosystem Research Group, Department of Crop, Soil \& Pest Management, Federal \\ University of Technology, Akure, Nigeria.
}

*Corresponding Authors: Agele, Plant Physiology \& Ecosystem Research Group, Department of Crop, Soil \& Pest Management, Federal University of Technology, Akure, Nigeria.

\begin{abstract}
An experiment was conducted at the Teaching and Research Farm, Federal University of Technology, Akure, in the rainforest zone of South-West Nigeria, to examine the residual effects of moisture stress of seedlings in the nursery on field performance of cacao genotypes. The experimental materials were two cacao genotypes (Amelonado and F3 Amazon) and two improved lines (PA 150/34 and PA 150/36) which were obtained from Cocoa Research Institute of Nigeria (CRIN), Ibadan. The seeds of the genotypes were sown in nursery pots, and seedlings were subjected to varying levels (0.6, 0.9 and 1.5 litres) of watering in the nursery. After ten (10) months in the nursery, the differentially watered seedlings were transplanted on the field in June, 2017. The experiment was laid out in a $4 \times 3$ factorial combination arranged in a Split Plot Design at three replicates per treatment. The cacao genotypes constituted the main plot while the differentially watered seedlings the sub-plot treatment. Data were collected on plant height (cm), stem girth $(\mathrm{mm})$, number of leaves, and number of branches, number of dead seedlings and number of seedlings bearing dead twigs/branches and final survival count at end of dry season. Results showed that the effects of cacao genotypes anddifferential watering of seedlings in the nursery were significant on the measured growth and development variables of cacao on the field. The development of leaves and solar radiation properties (incidence and transmitted radiation) within cacao canopy varied during the course of the year among treatments. Across the differentially watered seedlings, highest radiation transmission within canopy was obtained between January and April. The ratio of transmitted to incident radiation were lowest for $1.5 \mathrm{l}$ watered seedlings and lowest for moderate $(0.9 l)$ and severe water stressed $(0.6 l)$ seedlings. The effect of cacao genotype was pronounced on the time dynamics of canopy development (number of leaves and leaf area index), compared with F3 Amazon and the improved cacao varieties (the PA series), Amelonado had best leaf development across the measurement dates. Lowest number of leaves per plant were found for period between 360 - 90 DOY and highest between 150- 270 DOY (the dry and rainy season periods respectively. Within measurement periods, lowest LAI and highest PAR were observed at DOY 90 (February of a year) while highest LAI and lowest PAR between 180 and 360 DOY (between June and December of a year). The effect of differential watering was pronounced on seedling mortality on the field during the year, and lowest number of dead trees per treatment was obtained for the $1.5 \mathrm{l}$ watered seedlings and highest for 0.6 l. Highest number of trees bearing dead twigs/branches were observed during the dry season (360-90 DOY, December to March of a year) and lowest between 120 to 300 DOY (April to October). The survivability of seedlings on the field was high (75\%) irrespective of treatment received in the screen house. It is concluded that the effects of pre-field (nursery) water stress of seedling was profound on field performance of cacao genotypes.
\end{abstract}

Keywords: Drought, stress, species, distribution, cacao, growth, mortality, recovery

\section{INTRODUCTION}

Cacao (Theobroma cacao L.) belongs to the family Sterculiaceae and the genus Theobroma. Recently, with the application of molecular marker, cacao was reclassified to the family Malvaceae (Alvensonet al., 1999). Cocoa (Theobromacacao L.) is an evergreen tropical lowland tree crop, native to the rainforest regions of Central and South America and indeed West Africa, which became the major producer from the mid-1960s (Opeke, 2006). There are over twenty species in the genus but Theobromacacao is the only one cultivated widely (Opeke, 2006). It is a cash crop of international significance, and has been a major source of foreign exchange for producing countries. Cacao is highly valued for its seeds - the cocoa beans. West Africa is a dominant cocoa producing region, because of its suitable soil and favourable climatic conditions. 
Cocoa is one of the most important perennial type cultivation in the world, with an estimate world production of 3.6 Mt (FAO, 2012). Cocoa is a major cash crop in many tropical countries and it is produced within $10^{\circ} \mathrm{N}$ and $10^{\circ} \mathrm{S}$ of the equator where the climate is suitable for its growth. West Africa has been the center of cocoa cultivation for many decades, as two-thirds of the world's cocoa is produced in West Africa (CRIN, 2011). Globally, the six main world cocoa producers are Ivory Coast, Ghana, Indonesia, Nigeria,Brazil, and Cameroon in descending order.

Cacao plant is highly sensitive to changes in climate from hours of sunshine to rainfall and application of water, soil condition and particularly to temperature due to effects on evapotranspiration (Almeida et al., 2002, Anim-Kwapong and Frimpong, 2005, Agele et al., 2016a). Water account for large proportion of living weight of plants, is essential for many physiological functions and it is most critical at certain periods in the life of cacao. Legavre et al. (2006) and Daymond et al. (2004) asserted that varietal improvement for tolerance to abiotic and biotic stress factors has been identified as a priority of research programs of cocoa producing countries.

Several reports have recorded over the years, decline in vigour of growth and establishment percentage and vof transplanted cacao seedlings. There is increasing need to establish new cocoa fields, and or rehabilitate old and moribund plantations using more productive cocoa stock for increased productivity. These efforts had been hindered by poor vigour of growth and field establishment possibly due to inadequate or sub-optimum water application in the nursery, the residual effects of this phenomenon is poor field performance.

The Nigerian National Cocoa Breeding Programme through selection resulted in "Established Ability Elites" which had better yields and adapted to marginal and drought prone areas (CRIN, 2011). The Cocao Research Institute of Nigeria has developed sets of improved cocoa varieties. Improvement implies development of varieties that are high yielding, pest and disease tolerant, tolerant to environmental stress that have been registered by the National Centre for Genetic Resources and Biotechnology (NACGRAB) (CRIN, 2011).

Cocoa seeds are sown in pots in the nursery to raise seedlings. In the nursery and on the field, cocoa seedlings are subjected to variable soil moisture status (wet-dry cycles) during its growth (Agele et al., 2018). The establishment and rehabilitation of cocoa farms, aimed at replacing ageing and nonproductive cocoa stocks in the field may be limited by inadequacy of healthy cocoa seedlings (Famuwagun et al., 2017). Efforts to increase cocoa seedlings by smallholder farmers and seed production unit for plantation establishment through the raising of cocoa seedlings in the nursery is associated with poor vigour of growth and establishment (CRIN, 2011)

The seedling stage key stage in the life history of woody plants that is most critical in terms of dessication tolerance and follow up field survival. The aim of the study it to explore the effects of previous drought stress event especially in the nursery on field performance of seedlings of cacao genotypes and to explore the relationships between drought performance and the establishment of cacao on the field. The effects of inadequate (sub-optimal) water application may be profound on field establishment (growth, development and survival rate) Therefore it is necessary to investigate the effects of nursery management practices required toraise vigorous cocoa seedlings in thenursery, such as regimes of water application in the nursery and the imports of such practices on plantation establishment, optimum plant stand following planting out on the field.

In the tropics, the dry post rainy season is characterized by concurrent stresses of extremely high soil and air temperatures, solar radiation intensity and vapour pressure (atmospheric dryness) and soil moisture deficits (Agele et al., 2016b). These factors limit growth and yield of crops sown in the dry season. The effects of extreme growing environmental factors (temperature, light intensity, soil water availability and vapour pressure deficit) on plant growth and tissue water relations has been reported (Agele et al., 2006). Physiological variables such as water relations and stomatal gas exchange are physiological attributes important to plant survival of unfavourable weather conditions, although these attributes are influenced by plant species and environmental conditions, may however are important to the expression of potential for acclimation in a species under drought and high temperatures (Haeberle et al., 2016).

Drought events (frequency and severity) including $\left(1.5\right.$ to $\left.2^{\circ} \mathrm{C}\right)$ warming are expected to increase in the near future as result of the decrease of regional precipitation and the increase in evapotranspiration driven by global warming (Sheffield and Wood, 2008; Sheffield et al., 2012; Dias, 2007, Tombesia et 
al., 2018). Changes in the global water cycle in response to the warming over the 21 st century will not be uniform, and natural droughts are expected to set in quicker, to become more intense, and to last longer (Trenberth et al., 2014).Among all the natural hazards, drought ranks first in terms of the number of people directly affected (Agele et al., 2016). Thus, the understanding of how plants and crops adapt and behave under this scenario is a goal of primary importance to improve agricultural performance towards recurrent droughts and to address the challenges of climate change, consequently. Drought effects (in particular water stress) on the physiological behavior of annual and perennial species have been widely investigated (Fleta-Soriano, E., Munné-Bosch, S., 2016, Glenn et al., 2014, Tombesia et al., 2014, Fleta-Soriano and Munné-Bosch, 2016). Trees in areas vulnerable to drought are exposed to drought stress almost every year (recurrent drought) and this could naturally prime tree response to drought. In fact, plant stress 'memory', i.e. the structural, genetic, and biochemical modifications that have occurred because of stress exposure and which make water stress in comparison with non-previously stressed plants (Tyree et al., 2003, Glenn et al., 2014,Li et al. 2016, Tombesia et al., 2018).

Whole-plant responses to soil moisture deficit/drought stress involve complex, interacting mechanisms (e.g. desiccation tolerance and drought performance). Through integrated interaction of mechanisms such as desiccation tolerance and drought performance, study provided improved insight/understanding of the role of these mechanisms for drought performance possibly from enhanced desiccation tolerance (Glenn et al., 2014, Fleta-Soriano and Munné-Bosch, 2016, Tombesia et al., 2018). It is important to enhance insight of underlying mechanisms linking drought resistance to drought performance on the field and ability of plants to survive the wet-dry seasonal transitions and the terminal drought episodes of the dry seasons of the humid tropics. Such understanding would enhance insight into species distributions and ultimately forest species diversity.

Will recurrent drought over multiple years such as the seasonal wet-dry cycles of the rainforest zone of Nigeria improve plant resistance to drought. Will differential drought resistance of plant species and genotypes lead to differential survival during drought (drought performance under field conditions), and relevance to species distributions along ecological gradients of rainfall, topography, and soil type of the humid/wet tropics. The objectives of this study are to evaluate the effects of residual effects of watering regimes of seedlings of cacao genotypes in the nursery on field performance (growth development and survival) and to relate measured agronomic variables with soil moisture deficit stress tolerance in cocoa seedlings. The study provide in information that may be required for increased production of cacao seedlings capable of surviving the unfavourableweather conditions to which they are exposed particularly the dry season when planted out on the field. Findings from this study is expected to enhance understanding of the responses of cacao genotypes and improved varieties/hybrids to soil moisture deficit stress both in the nursery and following planting out on the field. Such information will be relevant to the development of sustainable management practices for the production of cocoa seedlings. The results will contribute to the development of improved nursery practices for the production of vigorous cocoa seedlings and optimum field establishment.

\section{MATERIALS AND MeTHODS}

An experiment was conducted at the Teaching and Research Farm, Federal University of Technology, Akure in the rainforest of zone of Nigeria to examine the residual effects of moisture stress in the nursery on field performance of seedlings of cacao genotypes. The experimental materials comprised of two cacao genotypes (Amelonado and F3 Amazon) and two improved lines (PA 150/34 and PA 150/36) which were obtained from Cocoa Research Institute of Nigeria (CRIN), Ibadan. The seeds of the genotypes were sown in nursery pots, and seedlings of each genotype were subjected to varying levels (0.6, 0.9 and 1.5 litres) of watering in the nursery. After ten (10) months in the nursery, the differentially watered seedlings from the nursery were transplanted on the field on 13th June, 2017. The experiment was laid out in a $4 \times 3$ factorial combination arranged in a Split Plot Design at three replicates per treatment. The cacao genotypes constituted the main plot while the differentially watered seedlings the sub-plot treatment. Three plants from each plot were tagged for data collection. Agronomic practices such as weeding and watering were done when necessary. Data were collected on plant height $(\mathrm{cm})$, stem girth $(\mathrm{mm})$, number of leaves, and number of branches, number of dead seedlings and number of seedlings bearing dead twigs/branches and final survival count at end of dry season. 


\subsection{Experimental Design and Data Collection}

The treatments were $4 \times 3$ factorial combinations of cocoa varieties and watering regimes, laid out in a Randomized Complete Block Design (RCBD) with three replications. After transplanting, three plants per variety for each watering regime were randomly tagged for data collection. At intervals of three weeks for seven months, data were collected on the following parameters:

Plant height (PLHT): The average height in $\mathrm{cm}$ of each tagged plant from the base of the plant to the point where branching begins, using a meter rule, Number of leaves (NOL): The total number of leaves per plant, Number of branches (NOB): The total number of branches per plant, Stem girth (SG): The diameter of the trunk of each tagged plant was taken with the aid of a vernier caliper.

Cacao leaf area index (LAI) and canopy light integrals (incident, transmitted and absorbed radiation, the ratio of radioactive measurements below and above the canopy and PAR) were measured using LAI2000 (Plant Canopy Analyzer Model, Delta T, UK) equipment. In order to avoid errors in nondestructive LAI measurements caused by direct solar radiation, measurements with the LAI2000 were conducted only at dawn or, if the sky was completely overcast, during the day. Records were taken on the number of leaves per plant, the total leaf number (TLN).

The growing degree days (GDD) accumulated during growth was calculated from the daily maximum (Tmax) and minimum (Tmin) temperatures measured at the Meteorological Station located $500 \mathrm{~m}$ in from the experimental site. The values of cardinal temperatures for cacao (base $(\mathrm{Tb})=15^{\circ} \mathrm{C}$; optimum $(\mathrm{To})=22^{\circ} \mathrm{C}$ and maximum $\mathrm{Tm}=34^{\circ} \mathrm{C}$ ). The cardinal temperatures used were $15^{\circ} \mathrm{C}$ for base temperature, below which no development takes place and $34^{\circ} \mathrm{C}$ for maximum temperature, above which development is zero. The growing degree days (GDD) was computed during growth of cacao using the algorithm as;

$\mathrm{GDD}=\Sigma([\mathrm{Tmax}+\mathrm{Topt}] *$ day $1-\mathrm{x} / 2)-\mathrm{Tb}$

where Tmax represents maximum air temperature, Topt represents optimum temperature, and $\mathrm{Tb}$ represents base (minimum) temperature of cacao 1-x represents the time interval during which measurements were made (day one to the last day). The calculation considers a linear, ascending function between the base and optimum temperatures and a linear, descending function between the optimum and maximum temperatures. The calculated degree days summed over duration of the experiment which gave the heat units accumulated during growth.

\subsection{Data Analysis}

The data obtained were subjected to analysis of variance (ANOVA) using the PROC GLM procedure of SAS version 9.1 (SAS Institute, Cary, NC, USA; Statistical Analysis System 2000), to test the significance of the treatment means. Mean effects that showed significant F-tests were separated with Duncan Multiple Range Test.

\section{ReSUlts}

\subsection{Weather Conditions During Period of Study for Cacao}

The seasonal weather pattern of within cacao is presented in Table 1 . The rainy (early and late) season (April to July and August to November) and the dry season (December to March) are characterized by higher air temperatures and lower relative humidity compared with the dry season (Table 1). On the average, the rainy seasons had relative humidity average of $71 \%$ ) and air temperature of $32.8 \mathrm{oC}$ compared with the dry season (December to March). Also, higher air temperature and VPD and lower relative humidity were found for the unshaded open sun cacao compared with the shaded plants.

Table1. Seasonal trends in weather variables within cacao field

\begin{tabular}{|c|c|c|c|c|c|c|c|c|c|c|c|c|}
\hline \multirow[t]{2}{*}{ Treatments } & \multicolumn{3}{|c|}{$\operatorname{PAR}\left(\mu \mathrm{mol} / \mathrm{m}^{2} / \mathrm{s}\right)$} & \multicolumn{3}{|c|}{$\mathrm{RH}(\%)$} & \multicolumn{3}{|c|}{ VPD (kPa) } & \multicolumn{3}{|c|}{ Temp. $\left({ }^{\circ} \mathrm{C}\right)$} \\
\hline & $\mathrm{a}$ & & $\mathrm{c}$ & & $\mathrm{c}$ & & & & & & & \\
\hline Moderate stress level (0.91) & 681 & 982 & 831 & 71 & 78 & 59 & 1.6 & 1.3 & 2.4 & 30 & 32 & 33.3 \\
\hline Extreme stress level $(0.61)$ & 951 & 1523 & 1229 & 65 & 72 & 51 & 1.9 & 1.5 & 3.2 & 35 & 32 & 37 \\
\hline Well watered plants (1.5l) & 528 & 669 & 974 & 70 & 75 & 54 & 1.7 & 1.4 & 2.7 & 31 & 32.7 & 34.2 \\
\hline
\end{tabular}

Major (a) and Minor (b) rainy season and dry $(c)$ season, relative humidity $(R H)$, temperature $(T)$ and vapour pressure deficit (VPD), photosynthetically active radiation, leaf area index (LAI), 
The transmission of solar radiation within cacao canopy varies during periods of measurement (December of a year to April of another) (Fig. 1). The cacao seedlings raised under 0.61 watering regime in the nursery had enhanced radiation transmission, this is closely followed by 0.91 watering and least under 1.51 watering regime. Across the differentially watered seedlings, highest radiation transmission was obtained between January and April (Figure 2). The ratio of transmitted to incident radiation were lowest for 1.51 watered seedlings and lowest for moderate $(0.91)$ and severely water stressed seedlings.

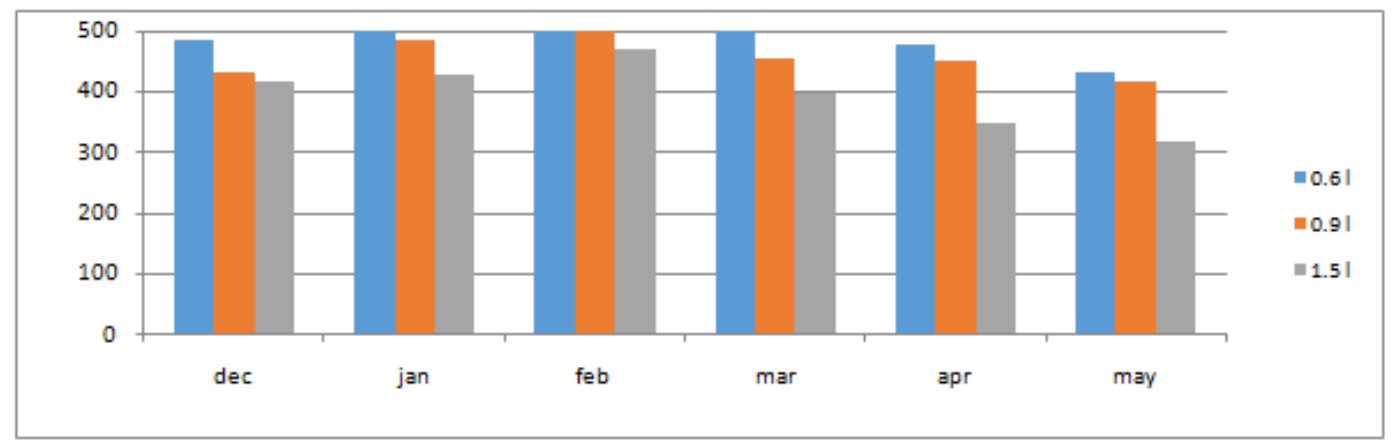

Fig1. The time course of transmitted radiation through cacao canopy

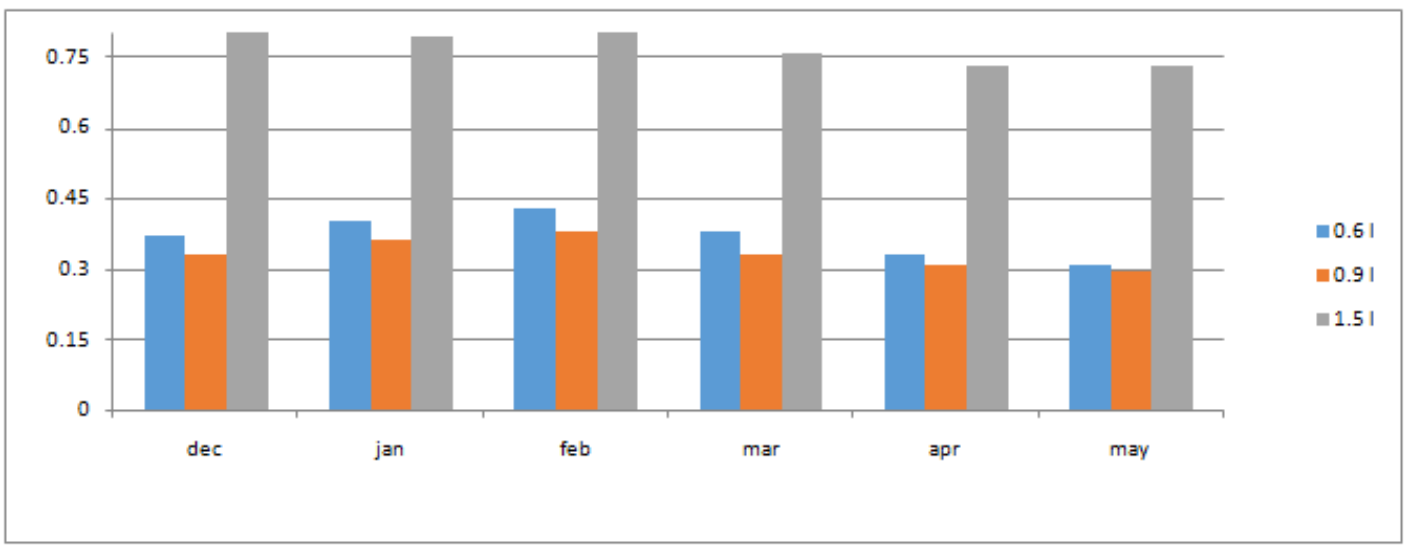

Fig2. The course of the ratio transmitted to incident radiation through cacao canopy

The course of leaf area index (LAI) and Photo synthetically Active Radiation (PAR) varied with measurement dates (from 270 to 90 day of year: DOY) especially with 3 and 21 months after transplanting (MAT) (Fig. 3). The canopy land cover indicated by LAI affected PAR intensity within cacao field. Hence, the trends observed for PAR were consistent with those of LAI. Within measurement periods, lowest LAI was obtained at DOY 90 (February of a year) and highest between 180 and 360 DOY (between June and December of a year). However, LAI increased with age of seedlings on the field (3 to 21 MAT) (Fig. 4).

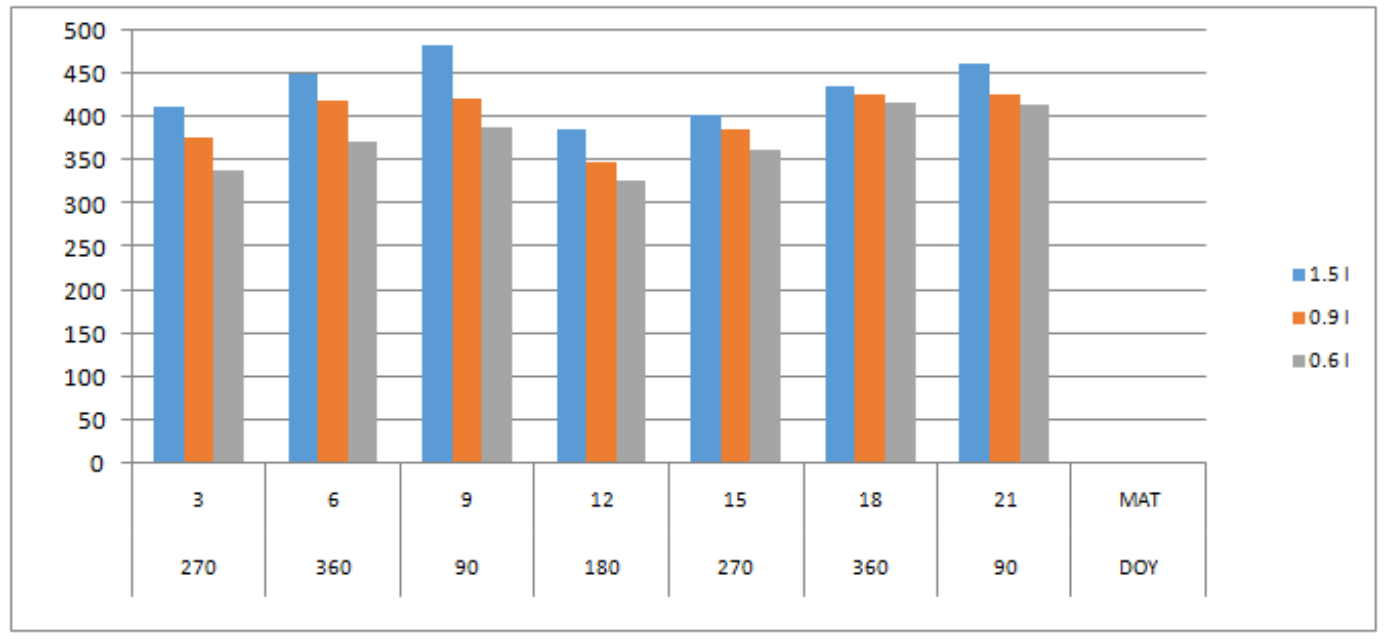

Fig3. Time course of PAR within cacao 


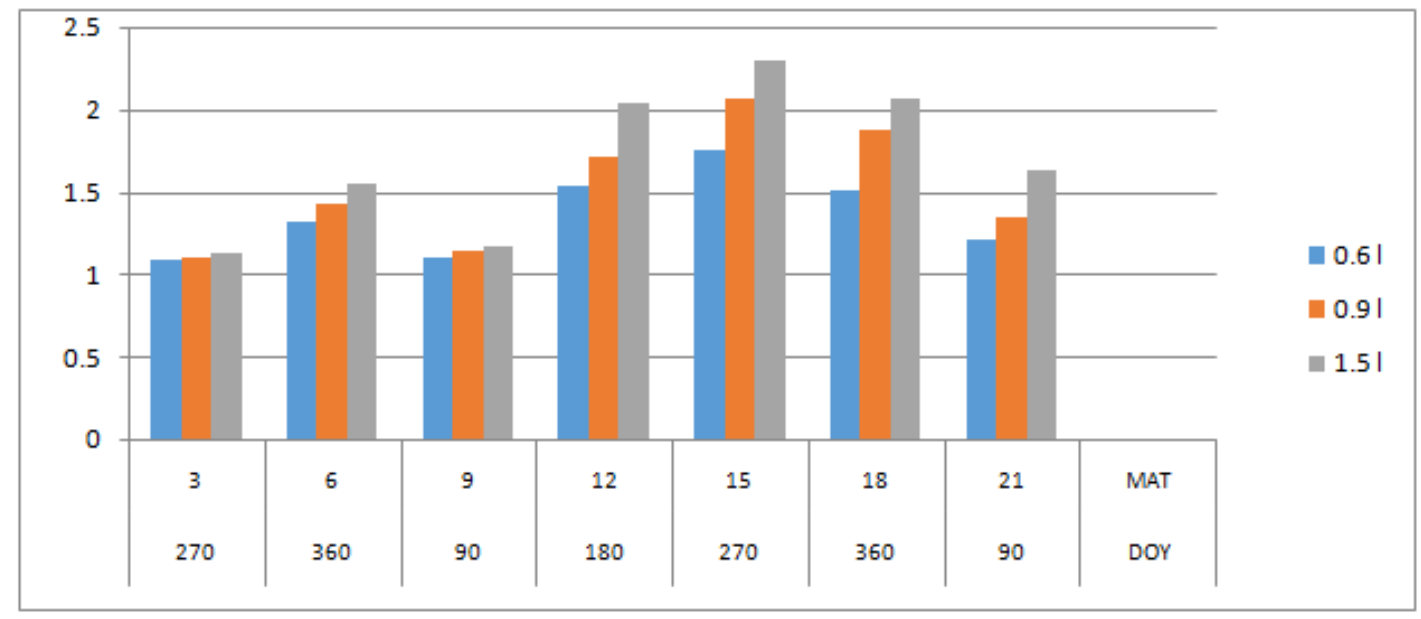

Fig4. Time course of LAI within cacao

The time course of leaf development (the number of leaves/plant), at the different measurement dates 210 - 360, 30- 360 and 30-90 DOY (September -December, January to December and January to March of each year showed variations in number of leaves/plant (Fig. 5). Lowest number of leaves per plant were found for period between 360 - 90 DOY and highest between 150- 270 DOY (the dry and rainy season periods respectively. Increases in leaf development commenced after onset of rain (90 to 240 DOY; March to August of a year) and sharp decreases (massive leaf drop) during the dry season (360 to 90 DOY). Compared with F3 Amazon and the improved varieties (the PA series), Amelonado genotype had best leaf development while the effect of differential watering in the nursery was not consistent on leaf development across the measurement dates. Height development on the field varied among the differentially $(0.6,0.9$ and 1.51$)$ watered seedlings in the nursery and among cacao genotypes (Fig. 6). Increase in height with seedlings age was obtained and consistently among differentially watered seedlings of cacao genotypes. Among the genotypes, Amelonado and F3 Amazon were taller than the hybrids (PA series). Plant height was not consistent among the differentially watered seedlings, a variable for which growth compensation appear to occur.

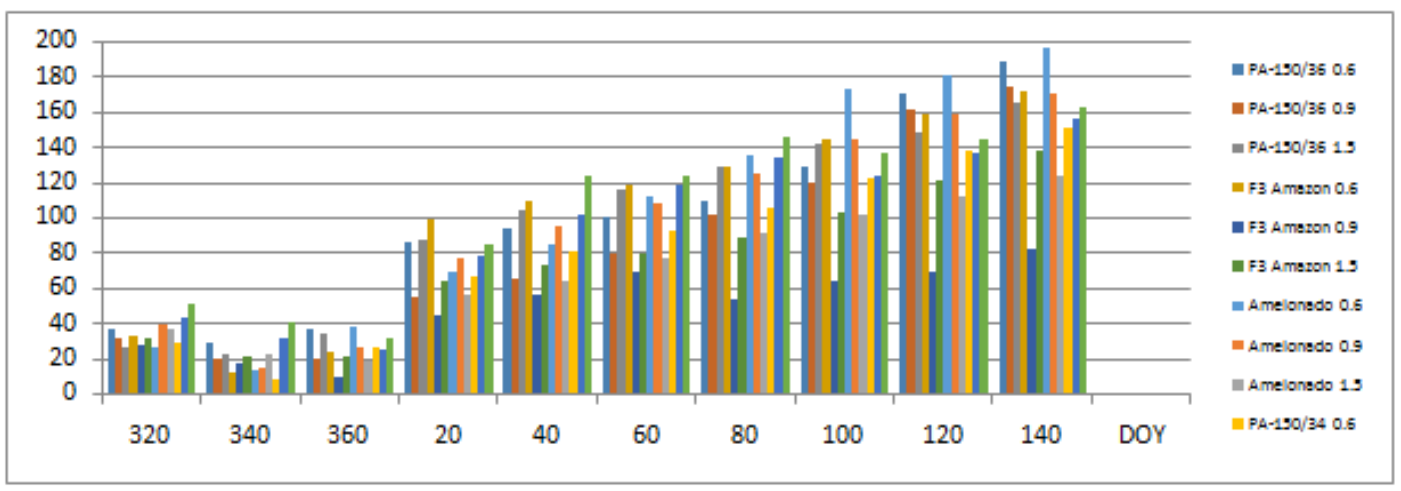

Fig5a. Time course of leaf development of cacao genotypes

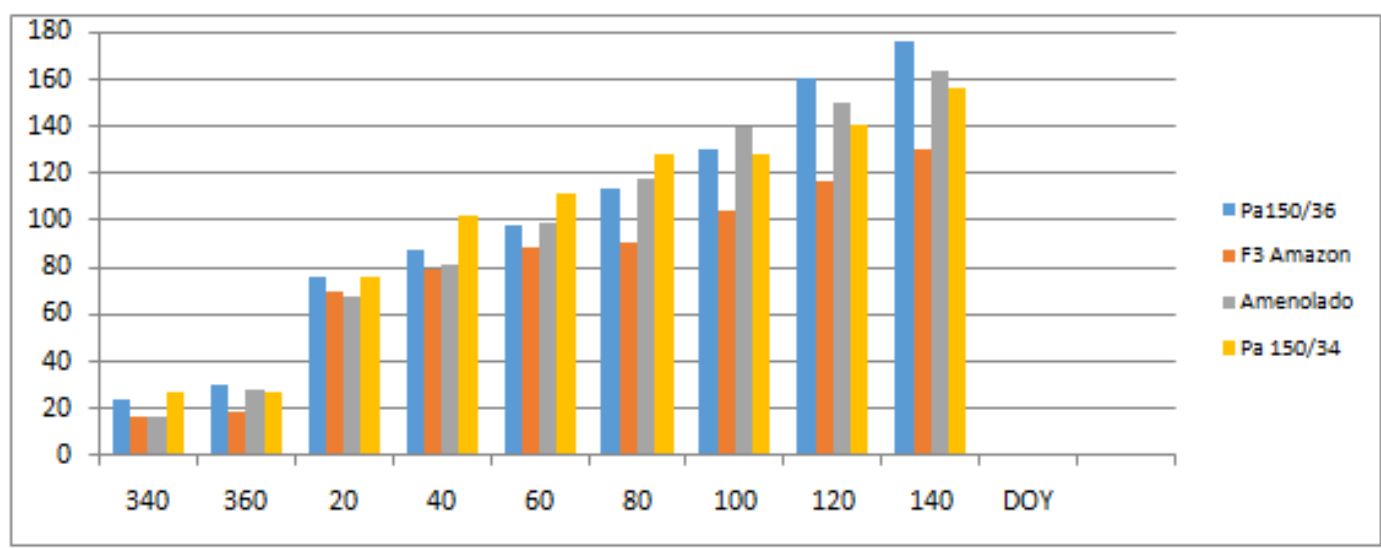

Fig5b. Time course of leaf development of cacao genotypes 


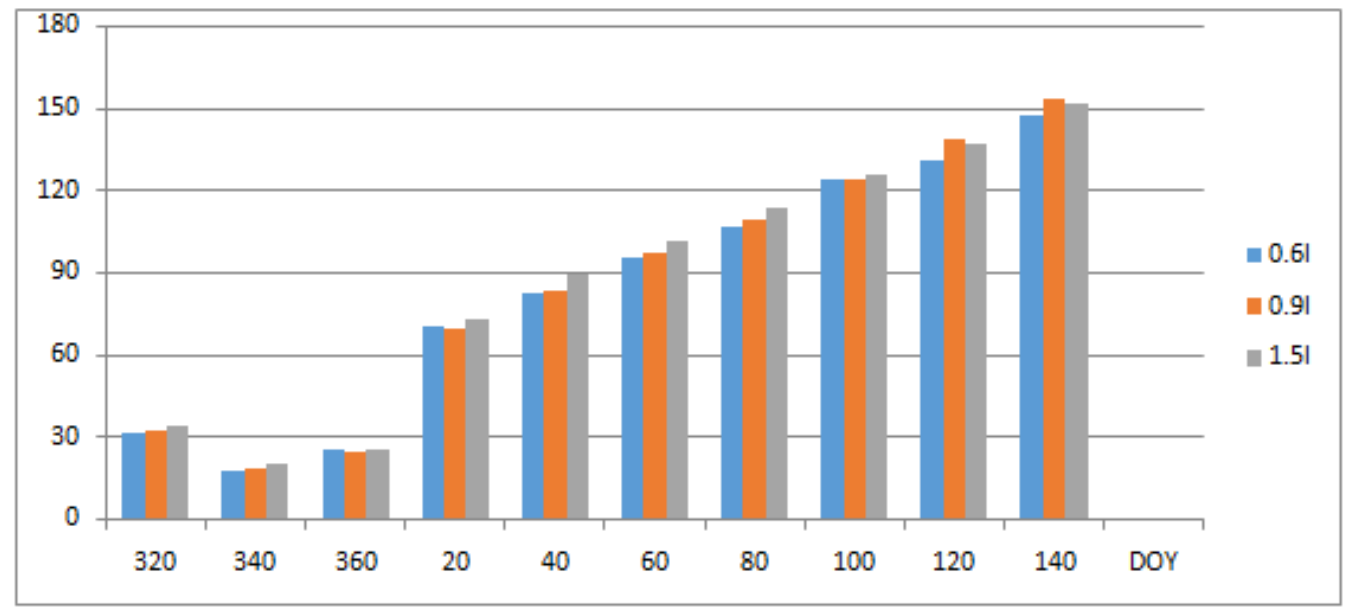

Fig5c. Time course of leaf development of differentially watered cacao

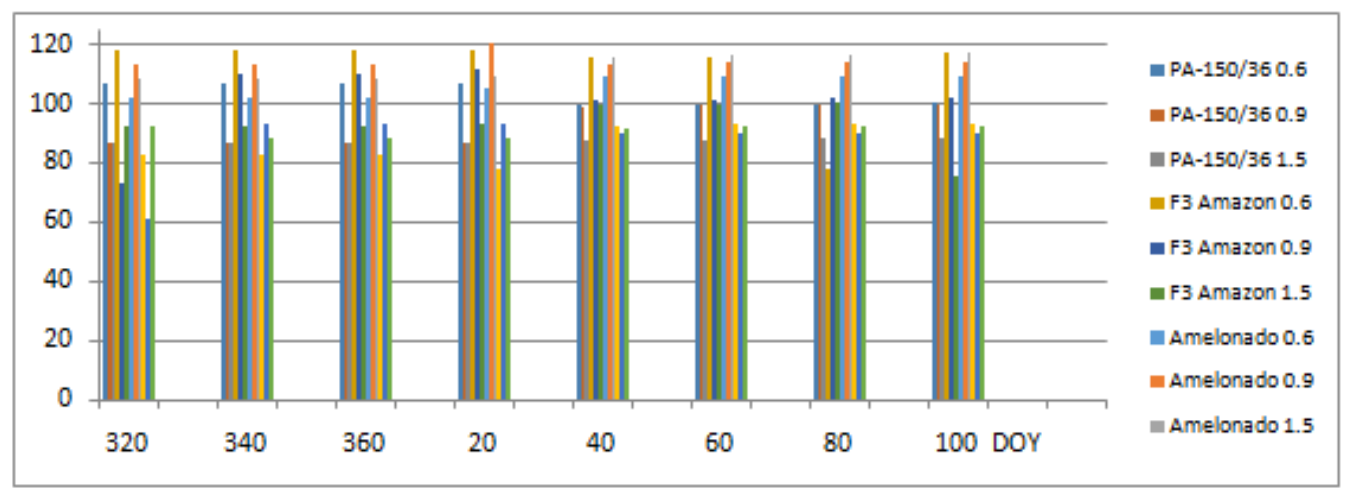

Fig6a. Time course of height development of cacao

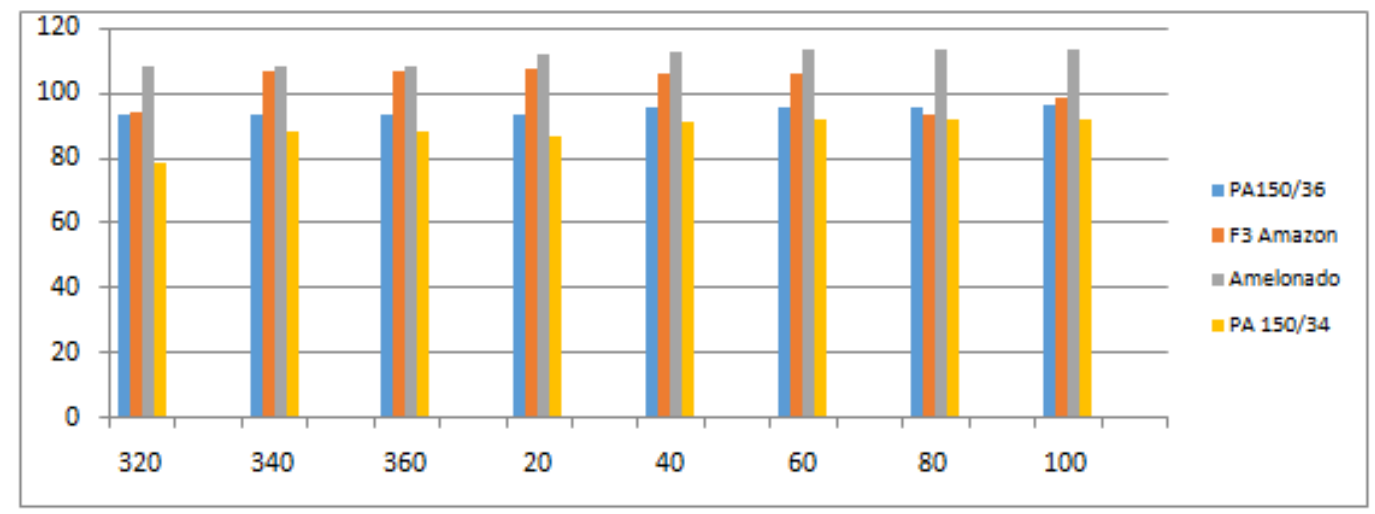

Fig6b. Time course of height development of cacao genotypes

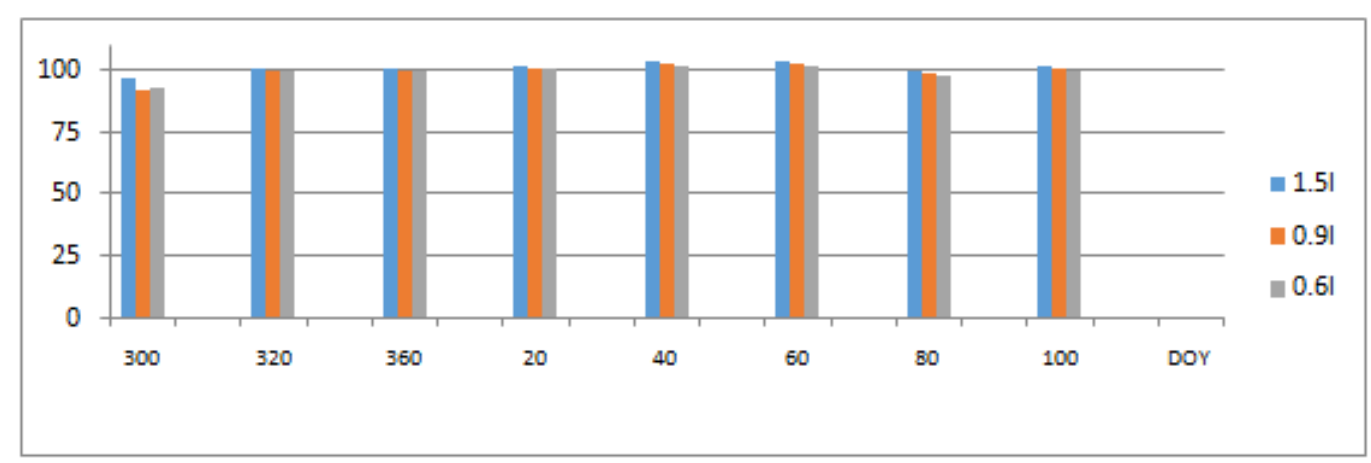

Fig6c. Time course of height development of differentially watered cacao

The pattern of stem diameter increases (stem girth) was similar to observations for plant height. Stem diameter increases on the field varied among the differentially $(0.6,0.9$ and 1.51$)$ watered seedlings in the nursery and among cacao genotypes (Fig.7). Increase in stem diameter with age was obtained and 
consistently among differentially watered seedlings of cacao genotypes. Among the genotypes, Amelonado and F3 Amazon were taller than the hybrids (PA series). Plant height was not consistent among cacao genotypes and the differentially watered seedlings.

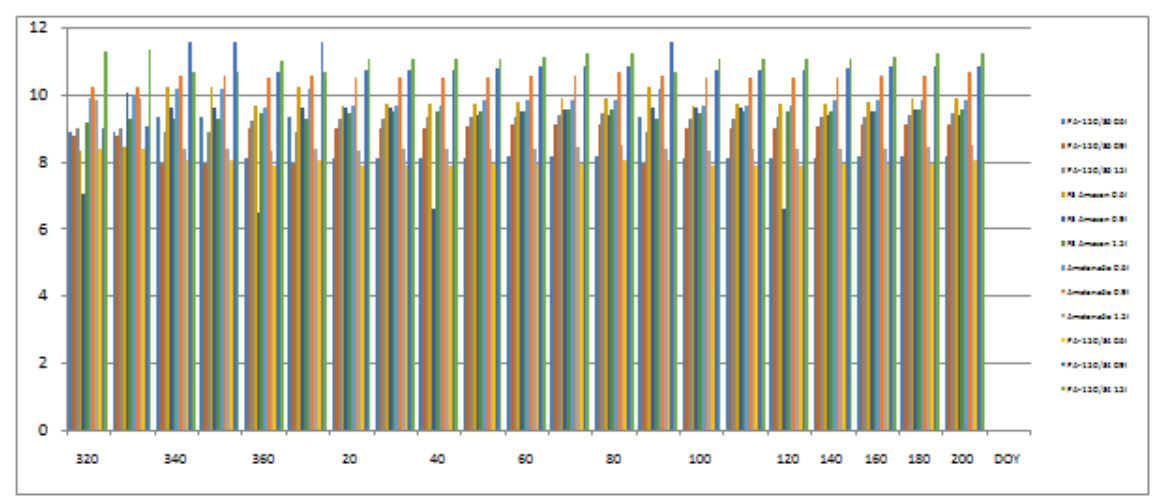

Fig7a. Effect of cacao genotype and pre-field water stress on the time course of stem girth development in cacao seedlings.

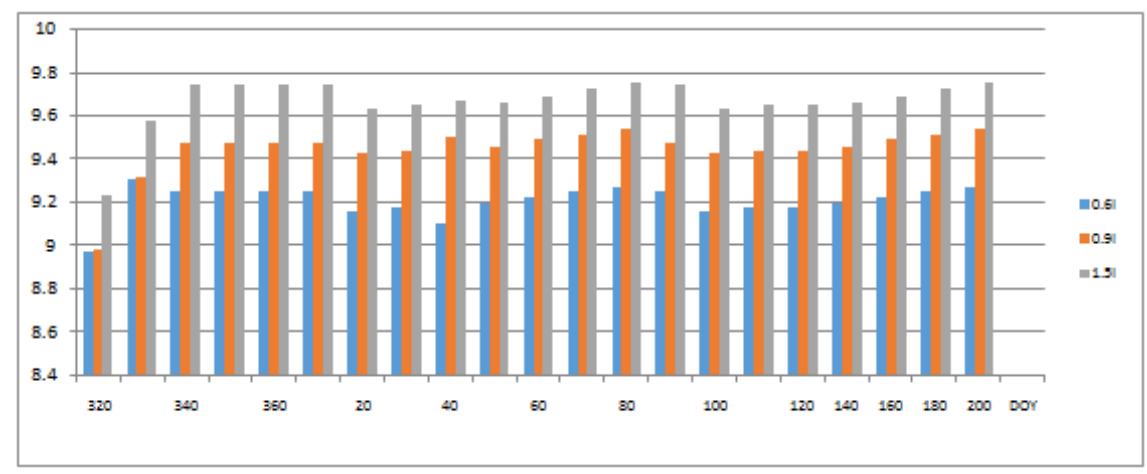

Fig7b. Effects of pre field water stress on the time course of stem girth development in cacao seedlings

The effect of differential watering in the nursery was pronounced on seedling mortality on the field especially in the dry season (360 -90 DOY, December to March of a year) (Fig. 8). The lowest number of dead trees per treatment was obtained for the 1.51 watered seedlings in the nursery and highest for 0.61 watering regime. Increases in the number of trees bearing dead twigs/branches were observed during the dry season (360-90 DOY, December to March of a year) and lowest between 120 to 300 DOY (Fig. 9). The highest number of dead trees per treatment was obtained for the 0.61 watered seedlings in the nursery and lowest for 1.51 watering regime. At the end of the dry season (end of experiment, $32 \mathrm{WAP}$ ), transplanted nursery stock of cacao that were raised on variable watering in the nursery show significant differences in their survival rates on the field (Table 7). The pattern of seedling survival of the nursery stock subjected to differential watering in the field showed that seedling batch that were raised under 0.61 watering regime have significantly lower $(\mathrm{p}<0.05)$ percentage survival (60\%) than those subjected to1 1 has $20 \%$ survival at the end of the dry season period (Table 7). Similarly, seedlings subjected to 0.91 have $70 \%$ survival which was lower than the $85 \%$ survival of the seedling batch raised under 11 watering.

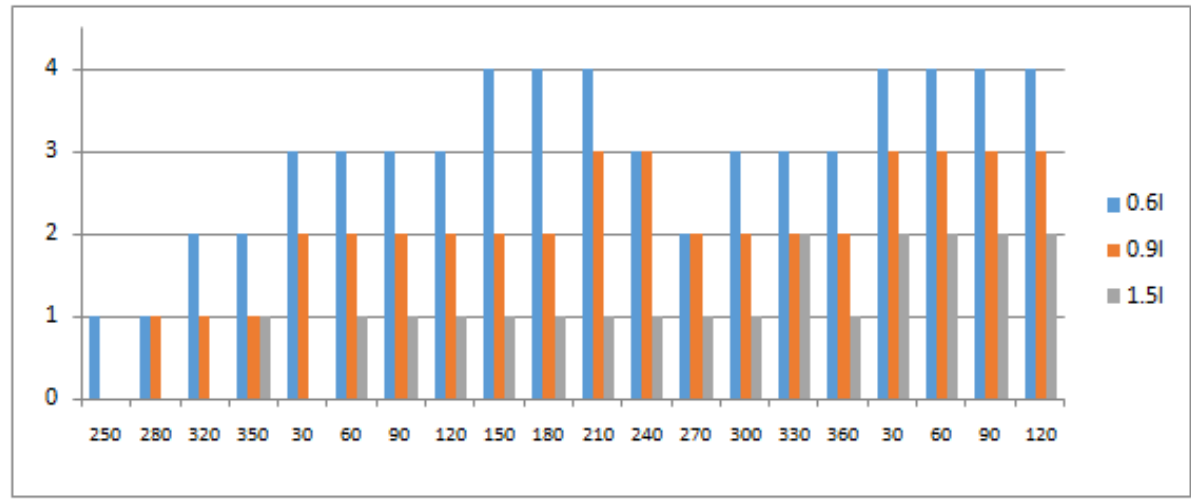

Fig8. Time course of number of dead trees per treatment 


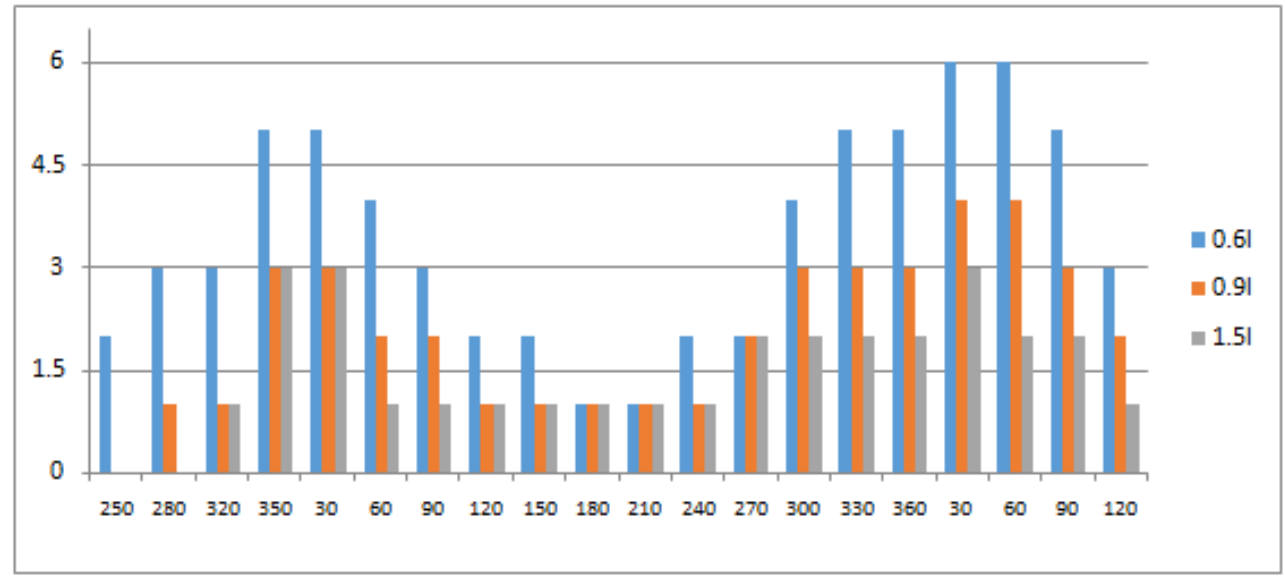

Fig9. Time course of number of trees per plot bearing dead twigs per treatment

\section{DISCUSSION}

There were gradients in the microclimate within cacao field during the course of the years. In the dry season the enhanced soil moisture deficit and high temperatures constraints cacao growth

The time periods within the year (wet and dry seasons) had varied intensities of soil and air moisture deficits and temperatures. The dry season had enhanced evapotranspiration (moisture loss from the soil and leaf surface) and consequently, the shoot (branch and twig) die-back and wilting (Daymondet al., 2004, Famuwagun et al., 2017). These results were supported by Zuidema et al. (2005) and Agele et al. (2016a) that moisture is the principal requirement for crop survival during the dry season to supplement soil moisture loss due to transpiration, evaporation and diminishing soil water enhanced by the dry and hot air. The results showed that the effects of cacao genotypes and watering regimes (soil moisture conditions under which seedlings were raised in the nursery (varying watering regimes) affected the measured growth and development variables of cacao.

Differences were obtained in field vigour of growth among the differentially watered cacao seedlings in the nursery. Compared with water stressed seedlings in the nursery, the well watered plants had enhanced vigour (branching and leaf area development) and lower mortality of whole trees and branch and twig die back syndrome of the dry season. The low status of soil moisture and high air and soil temperatures and sunlight intensity conditions appeared to have depressed cacao development in term of number of leaves and canopy extent (LAI). The findings were consistent with those of Kohler et al. (2010) and Daymond et al. (2004) that leaf and stem development in cacao will continue throughout the year if a conducive environment is provided in term of moisture, light and nutrients.

The time dynamics of leaf development and solar radiation properties (light integrals: incidence and transmitted radiation) within cacao canopy varied during the course of the year among treatments. Across treatments, highest radiation transmission within canopy was obtained between January and April, this period is the peak of the dry season. This observation is also attributable to the none or low rainfall and low soil moisture status and high temperatures of the dry season and the resultant lower leaf area formation and massive senescence. The ratio of transmitted to incident radiation were lowest for 1.51 watered seedlings and lowest for moderate $(0.91)$ and severe water stressed $(0.61)$ seedlings. Agele et al. (2016b) and Famuwagun et al. (2017) obtained high radiation intensity and transmission through cacao canopy during the dry season even for shaded cacao

The effects of cacao genotype and previous soil moisture conditions under which seedlings were raised were pronounced on the time course of canopy development (number of leaves and leaf area index). Lowest number of leaves per plant were found for period between 360 - 90 DOY and highest between 150- 270 DOY (the dry and rainy season periods respectively. Increases in leaf development commenced after onset of rain (90 to 240 DOY; March to August of a year) and sharp decreases (massive leaf drop) during the dry season (360 to 90 DOY). Kohler et al. (2010) and Famuwagun et al. (2017) reported seasonal differences in leaf and canopy development of cacao in the tropics.

Compared with F3 Amazon and the improved cacao varieties (the PA series), Amelonado had best leaf development while the effect of differential watering in the nursery was not consistent on leaf development across the measurement dates. Within measurement periods, lowest LAI and highest 
PAR were observed at DOY 90 (February of a year) while highest LAI and lowest PAR between 180 and 360 DOY (between June and December of a year). The seasonal trends obtained for LAI and PAR within cacao canopy follows from the rainfall distribution and the consequent wet-dry transitions of the humid tropics (Zuidema et al., 2005; Agele et al., 2016b). Height development on the field varied among the differentially $(0.6,0.9$ and $1.5 \mathrm{l})$ watered seedlings in the nursery and cacao genotypes for the respective wet and dry periods of the year. Increase in height with seedlings age was obtained and consistently among genotypes. Among the genotypes, Amelonado and F3 Amazon were taller than the hybrids (PA series). Height development was not consistent among the differentially watered seedlings. The inconsistency in height development by the differentially watered seedling in the nursery may be explained by poor prior vigour of growth and the time cost for compensatory growth on the field (Tombesiaet al., 2018).

The effect of differential watering in the nursery was pronounced on seedling mortality on the field during the year, and lowest number of dead trees per treatment was obtained for the 1.51 watered seedlings and highest for 0.61 . Highest number of trees bearing dead twigs/branches were observed during the dry season (360-90 DOY, December to March of a year) and lowest between 120 to 300 DOY (April to October). The highest number of dead trees per treatment was obtained for the 0.61 watered seedlings and lowest for 1.51 . The seasonal patterns found for plant mortality and percentage of trees bearing dead twigs/branches and treatment effects are attributable to unfavourable weather and soil conditions which enhanced physiological stress (Agele et al., 2016a). Plant mortality and death of twigs/branches in trees due to extreme weather, drought (soil moisture deficit stress) and high temperatures has been linked to physiological dysfunctions resulting from low photosynthesis (carbon starvation) and hydraulic (xylem water) transport incapacity (Agele et al., 2006, Haeberle et al., 2016).The seedling stage is the key stage in the life history of woody plants, is the most critical in terms of dessication tolerance, therefore, follow up study of field survival needed to be quantified. The ability of plants to survive field wet-dry seasonal transitions may be linked to previous stress history while good root development may confer ability to access soil water in particular (Tyree et al., 2003, Li et al. 2016).Thus, required is improvement in understanding of how plants and crops adapt and behave under wet-dry seasonal transitions may be linked to previous stress history is a goal of primary importance to improve agricultural performance towards recurrent droughts and to address the challenges of climate change (Fleta-Soriano and Munné-Bosch, 2016).In plants, the fitness of physiological functions under extreme growing environmental conditions such as soil moisture deficits or drought is important to a species acclimation to varying duration and intensities of drought (Haeberle et al., 2016).

\section{CONCLUSION}

After 22-week of regimes of wet dry cycles drought in the nursery, the seedlings of cacao genotypes were transplanted to field plots where observations were made on the growth and development and survival of the seedlings. The field trials were used to rank drought performance of cacao genotypes following nursery desiccation studies. The earlier experiment quantified desiccation tolerance in cacao seedlings in the nursery, the follow up experiment examined how such plants subjected to levels of wet-dry cycles survive after transplanting on the field thus offer opportunity for evaluation of drought performance under field conditions. The study provided improved insight of the interaction of mechanisms of desiccation tolerance and drought performance on the field using cacao genotypes. It is concluded that to the performance of seedlings of cacao genotypes subjected to wet-dry cycles in the nursery correlated with drought-performance under field conditions. The survival ability of seedlings of cacao genotypes. On the field was high $(70 \%)$ irrespective of treatment received in the nursery. The observed seedling mortality and branch and twig die-back may be attributed to soil moisture deficit and high temperature stresses during the dry season. Seedling mortality and branch and twig die-back would have implications for seedling vigour and field establishment in cacao; the seedling stage is the key stage in the life history of woody plants. Farmers should be encouraged to provide optimum watering for seedlings in the nursery to minimize mortality and enhance growth and establishment the ability of plants to survive under the wet-dry seasonal transitions may be linked to previous stress history. The study provide insight on the relative tolerance of pre-field water stressed seedlings of cacao genotypes to dry season soil and air moisture deficits and high temperature stresses and consequences for seedling vigour, survival (mortality) and field 
establishment. The consequences of pre-field water stress of seedlings of cacao genotypes on field performance (growth, development, vigour, survival and establishment) on the field.

\section{REFERENCES}

[1] Agele, S., S. Cohen, S. Assouline, S. 2006. Hydraulic characteristics and water relations of nethouse-grown bell pepper as affected by irrigation regimes in a mediterranean climate. Environmental \& Experimental Botany, 57:226-235

[2] Agele, S.O. 2007. Soil, plant and canopy resistance to water flow in bell pepper (Capsicum annuиm L.) as affected by fertigation regimes Journal of applied Horticulture 9(1): 56-61.

[3] Agele S.O, Iremiren G.O, Aiyelari O.P, Famuwagun I.B. 2016a. Mainstreaming adaptation, resilience and disaster risk reduction into extension of frontiers of cacao to marginal soils and climate of the humid tropics in the wake of climate and weather variabilities. $11^{\text {th }}$ Annual International Symposium on Environment, Athens, Greece.Athens Institute for Education and Research www.atiner.gr

[4] Agele S, Famuwagun B, Ogunleye A2016b. Effects of shade on microclimate, canopy characteristics and light integrals in dry season field-grown cocoa (Theobroma cacao L.) seedlings. Journal of Horticulture 11 (1); $47-56$.

[5] Agele S, Aiyelari P, Famuwagun B, Adegboye J, Oyeneyin E (2018).Effects of watering regime and mycorrhizalinoculation on seedling growth and drought tolerant traits of cocoa (Theobroma cacao L.) varieties. International Journal of Horticulture 8(13): 147-162 (doi: 10.5376/ijh.2018.08.0013)

[6] Alverson, W. S., Whitlock, B. A., Nyffeler, R., Bayer, C., and Baum, D. A. (1999). Phylogeny of the core Malvales: evidence from ndhF sequence data. Am. J. Bot. 86:1474-1486.

[7] Almeida A-AF, Brito RCT, Agular MAG, Valle PR. Water relations aspects of Theobroma cacao L. clones. Agrotropical 2002; 14: 35-44

[8] Anim-Kwapong GJ, FrimpongEB.Vulnerability of Agriculture to Climate - change impact of climate on Cocoa production.Cocoa Research Institute, New TafoAkim, Ghana 2005.

[9] Cocoa Research Institute of Nigeria (CRIN). Information Booklet- Quarterly Magazine 2011.CRIN News, Ibadan, Nigeria.

[10]Dias PC, Araujo WL, Moraes GABK, Barros RS, DaMatta FM. Morphological and Physiological responses of two coffee progenies to soil water availability. J Plant Physiol 2007; 164: 1639-1647

[11] Daymond AJ, Hadley P (2004). The effects of temperature and light integral on early vegetative growth and chlorophyll fluorescence of four contrasting genotypes of cacao (Theobroma cacao). Ann. appl. Biol.145: 257-262, 2004.

[12]Famuwagun B, Agele S, Aiyelari P (2017). Shade effects ongrowth and development of cacao following 2 years of continuous dry season irrigation.International Journal of Fruit Science 18(7), 1-24

[13]Fleta-Soriano, E., Munné-Bosch, S., 2016. Stress memory and the inevitable effects of drought: a physiological perspective. Front Plant Sci. 7, 143.

[14] Glenn, D.M., Kim, S.H., Ramirez-Villegas, J., Laderach, P., 2014.Response of perennial Horticultural crops to climate change. Horticultural Review 41, 47-130.

[15] Haeberle KH, Agele SO,Matyssek R, Hennlich M. Aspects of Water Relations and Gas Exchange of Katsura and Tilia Seedlings Subjected to Wet-Dry Cycles : Indication of Strategies for Whole Plant Drought Tolerance. Int J Plant Soil Sci 2016;10(2): 1 -13

[16] Kohler,M.,Schwendenmann, L. andHolscher, D. (2010). Throughfall reduction in a cacao agroforest: tree water use and soil water budgeting. Agricultural and Forest Meteorology 150, 1079-1089

[17]Legavre T, Gramacho K, Duchamp M, Sounigo O, Debert P, Fouet O, SabauX, ArgoutX, Wincker P, Da Silva C, LanaudC. Identification of Theobroma cacao genes differentially expressed during Phytophthora infection. Proceeding of the $15^{\mathrm{h}}$ International Cocoa Research Conference, Costa Rica. June 2006.

[18]Li, X., Liu, F., et al., 2016. Drought stress Memory and Drought stress tolerance in plants: biochemical and molecular basis. In: In: Hossain, M.A. (Ed.), Drought Stress Tolerance in Plants 1. Springer International Publishing, Swizerland, pp. 17-44.

[19] Opeke K (2006).Tropical commodity crops. Spectrum Books Ltd., Ibadan, Nigeria. 213pp.

[20] Sheffield, J., Wood, E.F., Roderick, M.L., 2012. Little change in global drought over the past 60 years. Nature 491, 435-438.

[21] Tombesia,S., Frionia, T., Ponia, S., Palliotti, A. 2018. Effect of water stress "memory" on plant behavior during subsequent drought stress. Environ Expt Bot, 150, 106-114

[22] Trenberth, K.E., Dai, A., Schrier van der, G., Jones, P.D., Barichivich, J., Briffa, K.R., Sheffield, J. 2014.Global warming and changes in drought. Nat. Clim. Change 4, 17-22. 
[23] Tyree, M.T., Engelbrecht, B.M.J., Vargas, G., and Kursar, T.A. 2003. Desiccation Tolerance of Five Tropical Seedlings in Panama. Relationship to a Field Assessment of Drought Performance. Plant Physiol. 132, 21 - 33.

[24]Zuidema PA, Peter A, Leffelaar PA, Gerritsma W, Mommer L, Niels PR,Anten NPR 2005.A physiological production model for cocoa (Theobroma cacao): model presentation, validation and application Agricultural Systems 84 (2005) 195-225

Citation: Agele, et.al, " Residual Effects of Moisture Stressed Seedlings in the Nursery on Field Performance of Cacao Genotypes", International Journal of Forestry and Horticulture (IJFH), vol. 5, no. 3, pp. 19-30, 2019. Available: DOI: http://dx.doi.org/10.20431/2454-9487.0503003

Copyright: (C) 2019 Authors. This is an open-access article distributed under the terms of the Creative Commons Attribution License, which permits unrestricted use, distribution, and reproduction in any medium, provided the original author and source are credited. 